\title{
LANDSLIDE IDENTIFICATION FROM IRS-P6 LISS-IV TEMPORAL DATA-A COMPARATIVE STUDY USING FUZZY BASED CLASSIFIERS
}

\author{
S. S. Sengar ${ }^{1, *}$, S. K. Ghosh ${ }^{2}$, A. Kumar ${ }^{3}$, H. Chaudhary ${ }^{4}$ \\ ${ }^{1}$ Electronics and Communication Department, JK Lakshmipat University, India - sssengar@jklu.edu.in \\ ${ }^{2}$ Civil Engineering Department, Indian Institute of Technology Roorkee, India - scanghosh@ yahoo.co.in \\ ${ }^{3}$ Scientist/Engineer- SG, Indian Institute of Remote Sensing, Dehradun, India - iirs_anil@yahoo.com \\ ${ }^{4}$ Electronics and Communication Department, Manipal University, Jaipur, India - himanshu.chaudhary@jaipur.manipal.edu
}

Commission VI, WG VI/4

KEY WORDS: Kashmir earthquake, CBSI, LISS-IV, Vegetation Index, Temporal, PCM

\begin{abstract}
:
While extracting land cover from remote sensing images, each pixel in the image is allocated to one of the possible class. In reality different land covers within a pixel can be found due to continuum of variation in landscape and intrinsic mixed nature of most classes. Mixed pixels may not be appropriately processed by traditional image classifiers, which assume that pixels are pure. The existence of mixed pixels led to the development of several approaches for soft (often termed fuzzy in the remote sensing literature) classification in which each pixel is allocated to all classes in varying proportions. However, while the proportions of each land cover within each pixel may be predicted, the spatial location of each land cover within each pixel is not. Thus, it is important to develop and implement a classifier that can work as soft classifiers for landslide identification. This work is an attempt to document and identify landslide areas by five spectral indices using temporal multi-spectral images from IRS-P6 LISS-IV images. To improve the spectral properties of spectral indices for specific class identification (in this case landslide) a Class Based Sensor Independent (CBSI) technique proposed. The result indicates that CBSI based Transformed Normalized Difference Vegetation Index (TNDVI) temporal indices data gives better results for landslide identification with minimum entropy and membership range.
\end{abstract}

\section{INTRODUCTION}

Remote sensing images dominated by mixed pixels tend to increase the error in classification. Conventional hard classifiers may tend to over and under estimate the actual aerial extends of the classes on the ground and incorporate more errors in the results. Further, when there is large numbers of mixed pixels present within an image, identification of sufficient number of pure pixels for training and testing parameters may not be possible. The contribution of each pixel is assigned in proportion to the percentage area each ground cover class occupies in that mixed pixel (Boardman 1989). Such an approach is called spectral un-mixing which assigns more than one class label to an individual mixed pixel (Keshava and Mustard 2002). However, the most promising area seems to be the application of remote sensing in sub-pixel classification, not widely used in the field of disaster events. For this reason, it has been proposed that fuzziness should be accommodated in the classification procedure so that pixels may have multiple or partial class membership and handle mixed pixel (Foody et al. 1997).

Examples of soft classification techniques applied to remotelysensed imagery include the linear mixture model (Adams et al., 1985; Foody and Cox, 1994; Garcia-Haro et al., 1996), fuzzy cmeans classification (FCM) (Bezdek, 1981; Bezdek et al., 1984), and feed-forward, back-propagation (FFBP) neural networks trained on class proportions (Benediktsson et al., 1990; Paola and Schowengerdt, 1995; Atkinson and Tatnall,
1997; Atkinson et al., 1997), support vector machines (Brown et al., 1999), among many others.

In FCM, the summation of class memberships of a pixel is equal to one, which is based on a probabilistic constraint. This constraint may have application where it is appropriate to interpret memberships as relative strength of class memberships (Krishnapuram and Keller, 1993). The major drawback of this constraint is that classes present in a pixel are inter-dependent, which may not be the case in reality. This may lead to inaccurate classification. In PCM clustering, (Krishnapuram and Keller, 1993, 1996) probabilistic constraint has been relaxed to produce absolute class memberships, which may indicate the class proportions in a pixel. This can produce more accurate soft classification results compared to FCM (Harris, 1981). For identification of landslides using coarse resolution remotely sensed data, the work is designed to meet the following objectives:

1. Identification of earthquake induced landslides area using coarse resolution satellite data.

2. Identification of landslides area as a specific class without merging it with other classes at sub-pixel level.

3. Improve the performance of different indices for specific class identification using CBSI technique.

4. Evaluate the outputs using entropy concept

\footnotetext{
* Corresponding author
} 


\section{STUDY AREA}

An earthquake of magnitude Mw 7.6 (USGS, 2005) shook entire northern India and northern Pakistan on 8 October 2005. The focal depth of the earthquake was $26 \mathrm{~km}$. The location of the earthquake epicentre $(34.493 \mathrm{oN}, 73.629 \mathrm{oE})$ was close to Muzaffarabad in Pakistan-administered Kashmir. The earthquake epicentre is very close to the Shinkiari fault, Jhelum fault and Main Boundary Thrust (MBT). The Jhelum fault is a major neotectonic fault and regionally most extensive. It is a north-south $(\mathrm{N}-\mathrm{S})$ trending left lateral wrench fault that separates Kashmir basin of India from the Peshawar basin of Pakistan (GSI 2000). The earthquake occurred in the region of the Himalayan frontal fold belt bounded by several tectonic features. The region seems to have a complex set-up, as seen on the tectonic map prepared by the Geological Survey of India (GSI 2000).

The epicentral tract lies in the Jhelum re-entrant, a part of the Hazara syntaxis structure, and is surrounded by the Main Boundary Thrust (MBT) on the east and north and by the Shinkiari Fault (SF) and the Jhelum Fault (JF) (see figure 1). The MBT ends abruptly against the $\mathrm{N}-\mathrm{S}$ trending SF and makes an arc over the earthquake zone. The SF is joined by another well-known NNW-SSE trending sinistral JF west of Muzaffarabad. The frontal Himalayan cover rocks have also been affected by folding. Folded hills west of the JF show a southward dragging effect, indicating that the western margin of the Indian plate has moved northwards along the Jhelum fault dragging the sediments west of the fault along with it. Other active faults present in the region are Reasi Fault (RT), Main Mantle Thrust (MMT), Tarbela Fault (TF), Attock Fault (AF), Khairabad-Panjal Thrust (KPT) and Nathiagali Thrust (NT) (Das et al. 2007)

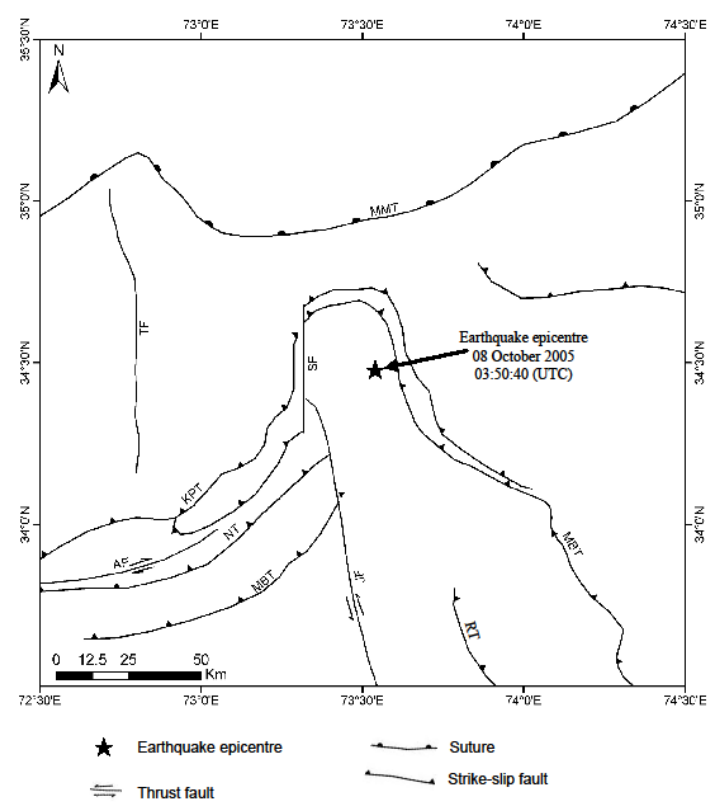

Figure 1: Tectonic set-up of the 8 October 2005 Kashmir earthquake region and surroundings (Modified from Das et al. 2007).
The local geology strongly indicates the possibility of large amplifications of ground motion owing to the influence Peshawar basin and basin edges near Jhelum fault. In this region of compressional tectonics, the motion between colliding geotectonic units is accommodated by slip on a suite of major thrusts. Furthermore, the modern deformation in the area is the result of north- and northeast-directed compression producing thrust faulting, which is evidenced by this deformation and warping of Pleistocene alluvial-fans into anticlinal ridges near the town of Muzaffarabad (about $10 \mathrm{~km}$ southwest of the earthquake epicentre) caused by northwest-southeast trending active thrust faults (Bilham 2006). This region is moderately active and has experienced several earthquakes of magnitude greater than $\mathrm{Mw}=5.0$ during last 300 years. The largest earthquake was on 30 May 1885 (Kashmir earthquake) and occurred $19.5 \mathrm{~km}$ west of Srinagar. The earthquake of Badgam (magnitude 5.1) on 2 September 1963 and Pattan (magnitude 5.9) on 28 December 1974 were the most deadliest and affected several towns in the region.

At present, use of earth resources satellite data is able to provide detailed information regarding such events which occur in poor accessible area. By acquiring temporal data, i.e. both pre and post event digital satellite images, it is possible to identify such phenomenon with relative ease and effectiveness. One of the main reasons is that spectral properties of the affected area will change as the electromagnetic energy interaction both temporal time frame i.e. pre and post event will be different. For the purpose of assessing damage at an early stage of a large earthquake, this work presents a method of landslide identification by temporal indices satellite data. Test data sets for this work have been acquired from LISS-IV sensor of IRS P6 satellite over two different acquisition dates, i.e., May 27th, 2005 (pre-earthquake fig.2a) and October 23rd, 2005 (postearthquake fig $2 b$ ) of the test site shown in figure 2 . The study area is covered by parts of the western Himalaya and major settlements covered in this study are in between Muzafarabad and Balakot city, Pakistan.

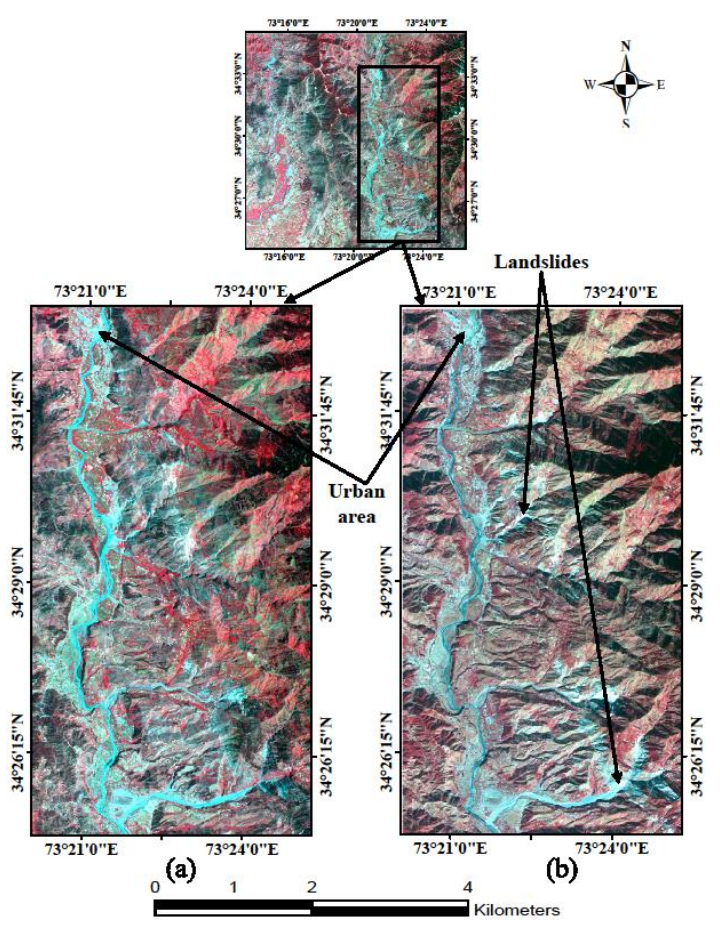

Figure 2. Study area 


\section{METHODOLOGY ADOPTED}

This study mainly focuses on identifying the landslide areas in and around Balakot-Muzaffarabad region after the Kashmir earthquake in 2005 . There has been requirement for identifying only one class that is, landslides. First of all, both pre- and postearthquake multi-spectral images have been atmospheric corrected using ATCOR-3 and geo-referenced using Autosync option of ERDAS software. To create the model of simple ratio indices, ERDAS Model Maker has been used. While using temporal multi-spectral data for classification in this work, the spectral dimensionality of each multi-spectral data has been reduced by using appropriate indices while class of interest is enhanced.

For generating band ratio data, it is important to know various types of band information present in multi-spectral data. While applying any band ratio, the user must be aware about number of bands along with their wavelength ranges. Based on spectral information of remote sensing data, the user has to decide which spectral bands of data are to be used in different band ratio functions and may require expert knowledge. To overcome the need for expert knowledge about remote sensing data, in this work CBSI spectral band ratio has been proposed as explained in Eq. (1) (Sengar 2013);

$$
C B S I(r, c)=\frac{g_{\text {nir }}(r, c)}{g_{\text {red }}(r, c)} \quad \forall(r, c) \in C_{k}
$$

where

$\mathrm{g}$ is grey value or digital number,

$\mathrm{r}$ and $\mathrm{c}$ are the row and column of pixels belonging to a class $C_{k}$ is kth class of the pixels,

$g_{\text {nir }}$ is the band for which the maximum grey value is found within the pixels belonging to the considered class; analogously, $g_{\text {red }}$ is the band of the minimum value.

In Eq. (1) the user has to provide the location of a class in the form of row and column or latitude and longitude. Based on coordinates of a class input, the minimum and maximum value of the data will be calculated. Apart from the class of interest (landslide) location, spectral information as grey value from all the bands will be read. Minimum and maximum operators finds out which band has minimum and which has maximum gray values. Then the band having maximum value is denoted as NIR and band having minimum values as RED in different indices as mentioned in Table 1. Here a simple condition is also applied that if indices values are negative then replace it with zero value. This enhances the concerned class of interest and only requires geo-location of a class, while spectral remote sensing data information is not required (Sengar 2014b,Sengar 2014c).

Now temporal database has been prepared using CBSI and conventional approach including mean indices values. These mean indices values helped in selection of band values for CBSI approach of interested class. Indices output from pre and post dated images have been layer stacked to prepare temporal indices data corresponding to spectral indices approach (as shown in Table.1). Two database (CBSI and conventional) was used to process using PCM classifier. In PCM classification, it has been presented how these temporal data (CBSI and conventional) along with a special form of possibilistic fuzzy classification data impact the accuracy of the temporal landslides classification.

In this section fuzzy based classifiers have been explained and the importance of possibilistic fuzzy based classifier for extraction of single class (landslide area) has been discussed. One of the fuzzy based classifier fuzzy c-means (FCM) is a clustering technique where each data point belongs to a cluster with some degree that is specified by a membership grade and that the sum of the memberships for each pixel must be one (Bezdek, 1981, Krishnapuram and Keller, 1993). This can be achieved by minimizing the generalized least-square error objective function as in Eq. (2);

$$
\mathrm{J}_{\mathrm{fcm}}(\mathrm{U}, \mathrm{V})=\sum_{k=1}^{N} \sum_{\mathrm{i}=1}^{\mathrm{C}}\left(\mu_{\mathrm{ki}}\right)^{\mathrm{m}} D\left(x_{k}, v_{i}\right)
$$

subject to constraints;

$$
\begin{aligned}
& \sum_{\mathrm{i}=1}^{\mathrm{C}} \mu_{\mathrm{ki}}=1 \quad \text { for all } \mathrm{k} \\
& \sum_{\mathrm{ki}=1}^{\mathrm{N}} \mu_{\mathrm{ki}}>0 \quad \text { for all } \mathrm{i} \\
& 0 \leq \mu_{\mathrm{ki}} \geq 1 \quad \text { for all } \mathrm{k}, \mathrm{i}
\end{aligned}
$$

and the class membership value is given as Eq. (3);

$$
\mu_{k, i}=\frac{1}{\sum_{j=1}^{c}\left(\frac{D\left(x_{k}, v_{i}\right)}{D\left(x_{k}, v_{j}\right)}\right)^{\frac{1}{m-1}}}
$$

Where

$D\left(x_{k}, v_{i}\right)=\sum_{j=1}^{c} D\left(x_{k}, v_{j}\right)$

$\mu_{k, i} \quad=$ a class membership values of a pixel $\mathrm{k}$ belonging to $\mathrm{i}$

$D\left(x_{k}, v_{i}\right)=$ Squared distance in feature space between $x_{k}$, and $v_{j}$ $D\left(x_{k}, v_{j}\right)=$ Squared distance in feature space between $x_{k}$, and $v_{j}$

${ }^{x} k=$ Vector denoting spectral response of a pixel $\mathrm{k}$

$v_{i}$

$$
\begin{array}{ll}
v_{i} & =\text { Collection of vector of cluster centers of class } \mathrm{i} \\
v_{j} & =\text { Collection of vector of cluster centers of class } \mathrm{j} \\
\mathrm{U} & =\mathrm{N} \times(\mathrm{c}+1) \text { matrix } \\
\mathrm{V} & =(\mathrm{v} 1, \mathrm{v} 2, \ldots \mathrm{vc}) \\
\mathrm{c} \text { and } \mathrm{N} & =\text { Total no. of clusters and pixels respectively } \\
\mathrm{m} & =\text { weighted constant }(1<\mathrm{m}<\infty)
\end{array}
$$

The squared distance $\mathrm{D}\left(x_{k}, v_{j}\right)$ between $x_{k}$, and $v_{j}$ which is given as Eq. (4);

$$
D\left(x_{k}, v_{i}\right)=\mathrm{d}_{\mathrm{ki}}^{2}=\left|\mathrm{X}_{\mathrm{k}}-\mathrm{V}_{\mathrm{i}}\right|_{\mathrm{A}}^{2}=\left(\mathrm{X}_{\mathrm{k}}-\mathrm{V}_{\mathrm{i}}\right)^{\mathrm{T}} \mathrm{A}\left(\mathrm{X}_{\mathrm{k}}-\mathrm{V}_{\mathrm{i}}\right)
$$

where A is the weight matrix; Amongst a number of A-norms, three namely Euclidean, Diagonal and Mahalonobis norm, each induced by specific weight matrix, are there. The formulations of each norm are given as (Bezdek, 1981); 


$\begin{array}{ll}\text { Euclidean Norm } & \mathrm{A}=\mathrm{I} \\ \text { Diagonal Norm } & \mathrm{A}=\sum_{i}^{-1} D \\ \text { Mahalonobis Norm } & \mathrm{A}=\sum_{i}^{-1} C\end{array}$

where $\mathrm{I}$ is the identity matrix, $D_{i}$ is the diagonal matrix having diagonal elements as the eigen values of the variance covariance matrix, $C_{i}$

given as Eq. (6);

$$
C_{i}=\sum_{\mathrm{k}=1}^{\mathrm{N}}\left(\mathrm{X}_{\mathrm{k}}-\mathrm{V}_{\mathrm{i}}\right)\left(\mathrm{X}_{\mathrm{k}}-\mathrm{V}_{\mathrm{i}}\right)^{\mathrm{T}}
$$

In this study, value of weighting exponent ' $m$ ' has been taken as 2.3 and Euclidean Norm of weight matrix ' $A$ ' has been taken, as it gives maximum classification accuracy compared to other weighted norms and less effected with noise outlier present in training data. As Euclidean Norm uses only mean value but other norms uses mean as well as variance-covariance. Mean is less affected than variance-covariance due to the presence of noise in training data (Kumar et al., 2006, Tso and Mather, 2009). The original FCM formulation minimizes the objective function as given in Eq. (2);

While in possibilistic fuzzy classifier one would like the memberships for representative feature points to be as high as possible, while unrepresentative points should have low membership in all clusters (Krishnapuram and Keller, 1993). The objective function, which satisfies this requirement, may be formulated as Eq. (7);

$$
\mathrm{J}_{\mathrm{pcm}}(\mathrm{U}, \mathrm{V})=\sum_{k=1}^{N} \sum_{\mathrm{i}=1}^{\mathrm{C}}\left(\mu_{\mathrm{ki}}\right)^{\mathrm{m}} D\left(x_{k}, v_{i}\right)+\sum \eta_{i} \sum\left(1-\mu_{\mathrm{ki}}\right)^{\mathrm{m}}
$$

subject to constraints;

$$
\begin{array}{ll}
{ }_{i}^{\max } \mu_{\mathrm{ki}}>0 & \text { for all } \mathrm{k} \\
\sum_{\mathrm{k}=1}^{\mathrm{N}} \mu_{\mathrm{ki}}>0 & \text { for alli } \\
0 \leq \mu_{\mathrm{ki}} \geq 1 & \text { for all } \mathrm{k}, \mathrm{i}
\end{array}
$$

In Eq. (7) $\eta_{i}$ is a parameter that depends on the distribution of pixels in the cluster $i$ and is assumed to be proportional to the mean value of the intra cluster distance. For clusters with similar distributions, $\eta_{i}$ may be set to the same value for each cluster (Massone, et al., 2000). Generally $\eta_{i}$ depends on the shape and average size of the cluster $i$ and its value may be computed as Eq. (9);

$$
\eta_{i}=K \frac{\sum_{k=1}^{N} \mu_{\mathrm{ki}}^{\mathrm{m}} D\left(x_{k}, v_{i}\right)}{\sum_{k=1}^{N} \mu_{\mathrm{ki}}^{\mathrm{m}}}
$$

here $\mu_{k, i}$ is taken from Eq. 3
Where $\mathrm{K}$ is a constant and generally kept equal to 1 . The class memberships $\mu_{k, i}$ are obtained as Eq. (10);

$$
\mu_{k, i}=\frac{1}{1+\sum_{j=1}^{c}\left(\frac{D\left(x_{k}, v_{i}\right)}{\eta_{i}}\right)^{\frac{1}{m-1}}}
$$

For extracting land cover classes, FCM is depended upon number of land cover classes to be extracted from remote sensing multi-spectral image. Membership values generated from Eq. 3, are depended upon summation of distances of unknown feature to mean vectors of land cover classes $\left[D\left(x_{k}, v_{i}\right)=\sum_{j=1}^{c} D\left(x_{k}, v_{j}\right)\right]$. When extracting only one land cover class of interest, in that case $\left.D\left(x_{k}, v_{i}\right)={ }^{D} x_{k}, v_{j}\right)$ for c equals to 1 and then $\mu_{k, i}$ for all features becomes one in Eq. 3 . This concludes that all features in remote sensing multi-spectral image belong to one class, which is not the case (Tso and Mather, 2009). Possibilistic fuzzy based classifiers do not follow probability rule. That means submission of occurrence of all classes in a pixel may not be one, as in the case of classifiers follows probability rule. While working with PCM algorithm for extracting single land cover class it behaves as: $D\left(x_{k}, v_{i}\right)=D\left(x_{k}, v_{j}\right)$, while extracting single land cover class $\mu_{k, i}=1$ for class features from Eq. 3 and $\sum_{k=1}^{N} \mu_{\mathrm{ki}}^{\mathrm{m}}=N$ So, from Eq. 9, $\eta_{i}=K \frac{\sum_{k=1}^{N} D\left(x_{k}, v_{i}\right)}{N}$ and from Eq. 10, $\mu_{k, i}$ will be calculated. This indicates that possibilistic view of the membership of a feature vector in a class has nothing to do with its membership in other classes (Krishnapuram and Keller, 1993).

The Automatic Land Cover Mapping (ALCM) module from Sub-Pixel Multi-Spectral Image Classifier (SMIC) package (Kumar et al. 2010) has been used generate output from PCM classifier. The ALCM module has the capability to process multiple multi-spectral images for single land cover class extraction at sub-pixel level using supervised approach with small training data set. The size of training data used for supervised sub-pixel classification approach was approximately equal to 10n (Jensen, 1996), were $\mathrm{n}$ is dimension (number of bands) of data used.

Assessing the accuracy of classified maps is an integral part while generating thematic classified map. The accuracy of classification is usually assessed by comparing the classification with some reference data that is believed to accurately reflect the true land cover. As occurrence of landslides due to earthquake is unique activity not occurring regularly in a hilly area. Secondly, while discriminating landslide areas through fraction images generated while using soft classifiers like fuzzy approaches; the fraction within pixel is not possible to locate on the ground. So, in this case, entropy as uncertainty indicator, an absolute indirect method for accuracy assessment has been used.

Shanon entropy (Foody, 1995) and fuzzy set based measures such as an index of fuzziness (Binaghi et al., 1999) may be used 
to estimate the uncertainty in the classification data. Entropy measures show how the strength of class membership in the classification output is partitioned between the classes for each pixel (Foody, 1996). The value of these measures is maximized (a high degree of uncertainty) when the class membership is partitioned evenly between all the classes, and minimized (a low degree or uncertainty) when the membership is associated entirely with one class. Shanon entropy, a measure conceptualized in terms of probability theory may be computed from Eq.(11) (Klir, 1990);

$$
H=-\sum_{i=1 k=1}^{c} \sum_{k=1}^{N} \mu_{\mathrm{ki}} \log \left(\mu_{\mathrm{ki}}\right)
$$

Therefore the accuracy assessment through entropy analysis using Eq. (11) was conducted for quality assessment. Entropy criterion is based on actual outputs of classifier and hence is sensitive to uncertain variations. Therefore this criterion can visualize the uncertainty of the classification results. The uncertainty can be controlled and its effects may be mitigated by removing the uncertainty causes and reasons. The uncertainty behavior is nearly independent of the correctness behaviour (Sengar 2014a). The uncertainty of the classification results gives a point of view about results quality and classifier performance, where each pixel may be classified with particular uncertainty. The results extracted from Eq. (11) shows that the pixels are classified with different quality and certainty. Therefore the certainty criteria can be used as a new comparison means for classifier performance (Hamid and Hassan, 2006).

Two dimensions are required to show the accuracy of output result, as it arises on a given set of testing data. One is True Positive Ratio (TPR) and another one is False Alarm Ratio (FAR). Low FAR (Eq. 13) and high TPR (Eq. 12) is desirable for good result (Brier and Allen, 1951).

No. of target detect as target

$\mathrm{TPR}=\overline{\text { Total no. } \text { of target presents in the sample }}$

No. of background detect as target

FAR $=\overline{\text { Total no. of background presents in the sample }}$

\section{RESULTS AND DISCUSSION}

Remote sensing techniques provide a rapid and powerful tool to identify spatial distribution of the co-seismic rupture zone associated with large earthquakes in the remote and high mountainous areas (Fu et al., 2004). The mean from training data landslide class generated from temporal indices data has been mentioned in Table 1 .

The Table. 1 clearly indicates that the mean indices value of interested class changed from pre earthquake to post earthquake data set. The higher mean value changes indicate that one class of interest easily separate with other classes. The various indices based on CBSI and conventional approach for landslides identification has been generated (figure 3 and 4). In these images landslide areas have high membership values and are seen as bright areas. The results of the same have super imposed on the corresponding landslide areas on indices images. If this temporal index variation is more from a specific index, than more nicely landslides can be distinguished.

\begin{tabular}{|c|c|c|c|c|}
\hline \multirow{2}{*}{ Spectral indices } & \multicolumn{4}{|c|}{ Landslides } \\
\cline { 2 - 5 } & \multicolumn{3}{|c|}{ CBSI } & \multicolumn{2}{c|}{ Conventional } \\
\cline { 2 - 5 } & Pre & Post & Pre & Post \\
\hline NDVI(Rouse et al. 1973) & 0.47 & 0.64 & 0.58 & 0.33 \\
& 2 & 4 & 9 & 0 \\
\hline SAVI(Huete 1988) & 0.47 & 0.64 & 0.58 & 0.33 \\
& 2 & 4 & 9 & 0 \\
\hline SR(Birth and McVey & 0.44 & 0.62 & 0.37 & 0.35 \\
$1968)$ & 1 & 1 & 5 & 1 \\
\hline TNDVI(Tucker 1979) & 0.83 & 0.92 & 0.88 & 0.74 \\
& 0 & 9 & 2 & 9 \\
\hline TVI(Broge and Leblanc & 0.73 & 0.56 & 0.65 & 0.48 \\
2000) & 0 & 0 & 6 & 8 \\
\hline
\end{tabular}

Table 1: Mean values from temporal indices data

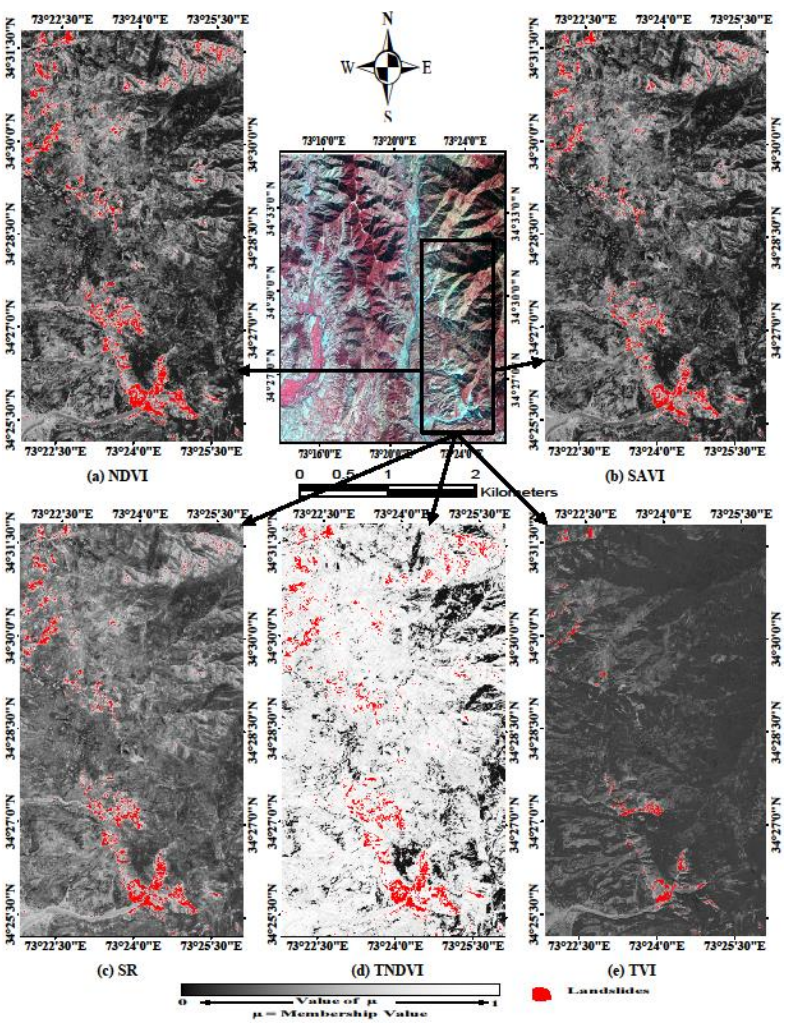

Figure 3. CBSI temporal indices output for landslides identification

\begin{tabular}{|c|c|c|c|c|}
\hline \multirow{2}{*}{$\begin{array}{c}\text { Temporal } \\
\text { Indices }\end{array}$} & \multicolumn{4}{|c|}{ Landslides } \\
\cline { 2 - 5 } & $\begin{array}{c}\text { Membership } \\
\text { values }\end{array}$ & Entropy & $\begin{array}{c}\text { Membership } \\
\text { values }\end{array}$ & Entropy \\
\hline NDVI & $0.898-0.996$ & 0.045 & $0.890-0.996$ & 0.034 \\
\hline SAVI & $0.910-0.996$ & 0.017 & $0.890-0.996$ & 0.028 \\
\hline SR & $0.910-0.996$ & 0.060 & $0.898-0.996$ & 0.118 \\
\hline TNDVI & $0.980-0.996$ & 0.011 & $0.914-0.996$ & 0.060 \\
\hline TVI & $0.820-0.996$ & 0.323 & $0.847-0.996$ & 0.343 \\
\hline
\end{tabular}

Table 2. Membership range and entropy value for landslides

Table 2 indicates that for landslides identification TNDVI temporal indices data shows best result with minimum membership range and minimum entropy value. But if both CBSI and conventional TNDVI indices result compare with each other then it is found that CBSI-TNDVI shows best result 
with membership range (0.980-0.996) and minimum entropy (0.011). The less membership range indicates that the class of interest can easily be identified without being overlapping with other classes. Similarly, less entropy indicates that there is less uncertainty in the class of interest.

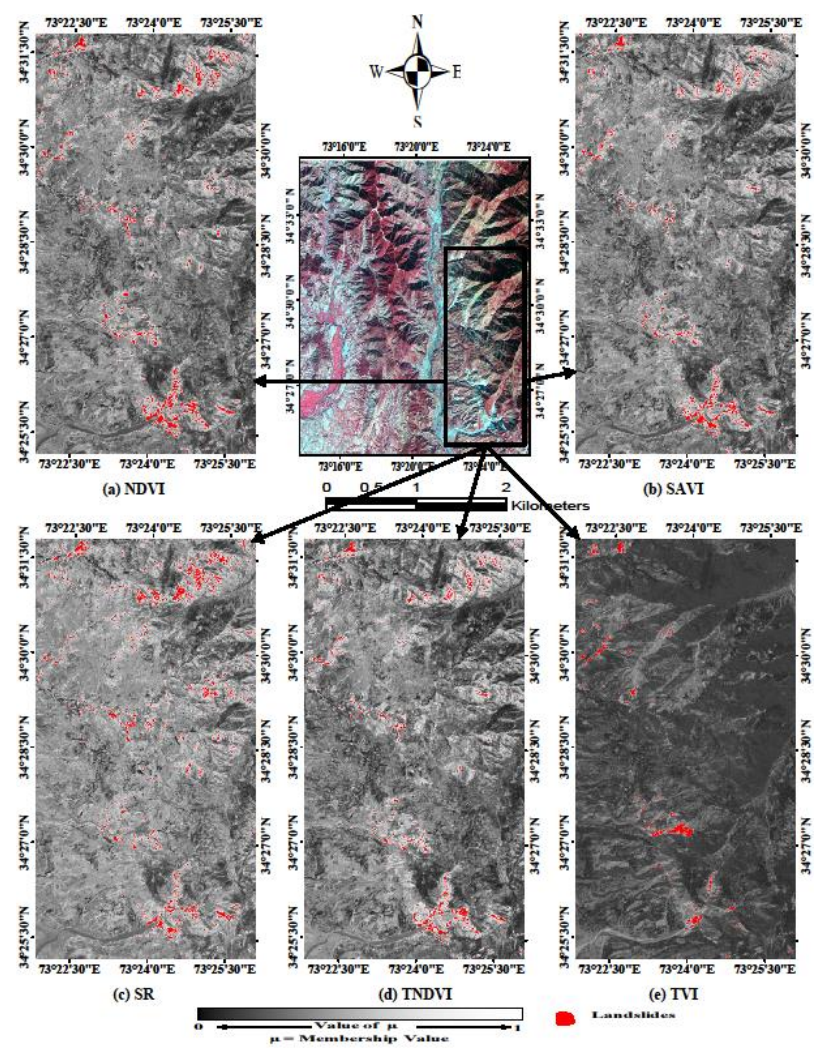

Figure 4. Conventional temporal indices output for landslides identification

\section{CONCLUSION}

In this study, importance of temporal indices has been studied for extracting landslide using PCM classifier. From results it was observed that using CBSI-TNDVI temporal indices show better separation between landslide and background as compare to other temporal indices result. The entropy analysis shows that using CBSI temporal indices data, the one class of interest (landslide area) was better identified in comparison to conventional indices data. The methodology proposed in this work requires minimal reference data as training sample and less information requirement about image characteristics for identification landslides. This methodology provides a quick and efficient way to identify landslides locations and may be useful for management and development plans for decision makers, local administrations, and scientists interested in landslides.

\section{REFERENCES}

Adams, J.B., Smith, M.O. and Johnson, P.E., 1985. Spectral mixture modeling: a new analysis of rock and soil types at the Viking Lander 1 site. Journal of Geophysical Research, 91(B8), pp. 8098-8112.

Atkinson, P.M. and Tatnall, A.R., 1997. Introduction: neural networks in remote sensing. International Journal of Remote Sensing, 18(4), pp. 699-709.
Atkinson, P.M., Cutler, M.E.J. and Lewis, H., 1997. Mapping subpixel proportional land cover with AVHRR imagery. International Journal of Remote Sensing, 18(4), pp. 917-935. Benediktsson, J.A., Swain, P.H. and Ersoy, O.K., 1990. Neural network approaches versus statistical methods in classification of multisource remote sensing data. IEEE Transactions on Geoscience and Remote Sensing, 28(4), pp. 540-552.

Bezdek J.C., 1981. Pattern Recognition with Fuzzy Objective Function Algorithm, Plenum, New York, USA.

Bezdek, J.C., Ehrlich, R. and Full, W., 1984. FCM: The fuzzy cmeans clustering algorithm. Computers and Geosciences, 10(23), pp. 191-203.

Bilham, R. and Hough, S.E., 2006. Future earthquakes on the Indian Continent: Inevitable hazard, preventable risk. South Asia Journal, 12, pp. 1-9.

Binaghi, E., Brivio, P.A., Chessi P. and Rampini A., 1999. A fuzzy Set based Accuracy Assessment of Soft Classification. Pattern Recognition letters, 20(9), pp.935-948.

Birth, G.S. and McVey G., 1968. Measuring the color of growing turf with a reflectance spectroradiometer. Agronomy Journal, 60(6), pp.640-643.

Boardman, J.W., 1989. Inversion of imaging spectrometry data using singular value decomposition, Proc. IGARSS'89, 12th Canadian Symposium on Remote Sensing, 4(43), 2069-2072.

Brier, G.W. and Allen, R.A., 1951. Verification of Weather Forecasts, Compendium of Meteorology, American Meteorological Society (T. Malone, ed.), pp. 841-848.

Broge, N.H. and Leblanc E., 2000. Comparing Predicting Power and Stability of Broadband and Hyperspectral vegetation Indicies for Estimation of green area index and canopy Chlorophyl density. Remote Sensing Environment, 76(2), pp.152-172.

Brown, M., Gunn, S.R. and Lewis, H.G., 1999. Support vector machines for optimal classification and spectral unmixing. Ecological Modelling, 120(2-3), pp. 167-179.

Das, J.D., Saraf, A.K. and Panda, S., 2007. Satellite data in a rapid analysis of Kashmir earthquake (October 2005) triggered landslide pattern and river water turbidity in and around the epicentral region. International Journal of Remote Sensing, 28(8), pp.1835-1842.

Foody, G.M., 1995. Cross-entropy for the evaluation of the accuracy of a fuzzy land cover classification with fuzzy ground data. ISPRS Journal of Photogrammetry and Remote Sensing, 50(5), pp. 2-12.

Foody, G.M., 1996. Approaches for the production and evaluation of fuzzy land cover classifications from remotely sensed data. International Journal of Remote Sensing, 17(7), pp. 1317-1340.

Foody, G.M. and Cox, D.P., 1994. Sub-pixel land cover composition estimation using a linear mixture model and fuzzy membership functions. International Journal of Remote Sensing, 15(3), pp. 619-631.

Fu, B., Lin, A., Kano, K.I., Maruyama, T. and Guo, J., 2004. Application of stereoscopic satellite images for studying Quaternary tectonics in arid regions. International Journal of Remote Sensing, 25(3), pp. 537-547.

Garcia-Haro, F.J., Gilabert, M.A. and Melia, J., 1996. Linear spectral mixture modelling to estimate vegetation amount from optical spectral data. International Journal of Remote Sensing, 17(17), pp. 3373-3400.

Geological Survey of India (GSI), 2000. Western Himalayan syntaxis between Kohistan arc and Potwar Plateau. Seismotectonic Atlas of India and its Environs, pp. 4-5. 
Jensen, J.R. (second ed.), 1996, Introductory Digital Image Processing: A Remote Sensing Prospective, (USA : Prentice Hall PTR).

Hamid, D. and Hassan, G., 2006. Measurement of uncertainty by the entropy: application to the classification of MSS data. International Journal of Remote Sensing, 27(18), pp.40054014.

Harris, R., 1981. Frameworks for the analysis of Landsat digital data, Environment and Planning, 13(12), pp. 1553-1562.

Huete, A.R., 1988. A soil-adjusted vegetation index (SAVI). Remote Sensing of Environment, 25(3), pp.295-309.

Keshava, N. and Mustard, J.F., 2002. Spectral unmixing. IEEE Signal Processing, 19(1), pp. 44-57.

Klir, G.J., 1990. A principle of uncertainty and information variance. International Journal of General Systems, 17(2-3), pp.249-275.

Krishnapuram, R. and Keller, J.M., 1993. A possiblistic approach to clustering. IEEE Transactions on Fuzzy Systems, 1(2), pp.98-108.

Krishnapuram, R. and Keller, J.M., 1996. The possibilistic cmeans algorithm: Insights and recommendations. IEEE Transactions on Fuzzy Systems, 4(3), pp. 98-108.

Kumar, A., Ghosh, S.K. and Dadhwal, V.K., 2006, A comparison of the performance of fuzzy algorithm versus statistical algorithm based sub-pixel classifier for remote sensing data, Proceedings of mid-term symposium ISPRS, The Netherlands May 2006. pp. 8-11.

Kumar, A., Ghosh, S.K. and Dadhwal, V.K., 2010. ALCM: Automatic land cover mapping, Journal of Indian Society of Remote Sensing, 38(2), pp.239-245.

Massone, A.M., Masulli, F. and petrosini, A., 2000. Fuzzy clustering algorithms and landsat images for detection of waste areas: A comparison, in Advances in Fuzzy Systems and Intelligent Technologies, Maastricht, The Netherlands: Shaker, pp.165-175.

Paola, J.D. and Schowengerdt, R.D., 1995. Review article: A review and analysis of backpropagation neural networks for classification of remotely sensed multispectral imagery. International Journal of Remote Sensing, 16(16), pp. 30333058.

Rouse, J.W., Haas, R.H., Schell, J.A., and Deering, D.W., 1973. Monitoring vegetation systems, in Third ERTS Symposium, NASA SP-351-I, 10-14 Dec. 1973, Washington, DC; United States, pp.309-317.

Sengar, S.S., Kumar, A., Ghosh, S.K., Wason, H.R., Raju, P.L.N., and Krishnamurthy, Y.V.N., 2013. Earthquake induced built-up damage identification using fuzzy approach. Geomatics, Natural Hazards and Risk, 4(4), pp.320-338.

Sengar, S.S., Kumar, A., Ghosh, S.K., Wason, H.R., Raju, P.L.N., and Krishnamurthy, Y.V.N., 2014a. Study of soft classification approaches for identification of earthquake induced liquefied soil. Geomatics, Natural Hazards and Risk, 5(4), pp.334-352.

Sengar, S.S., Kumar, A., Ghosh, S.K. and Wason, H.R., 2014b. Earthquake damage identification - a case study using soft classification approach. Natural Hazards, 71(3), pp.1307-1322. Sengar, S.S., Kumar, A., Ghosh, S.K. and Wason, H.R., 2014c. Earthquake induced built-up damage identification using IRSP6 data - a comparative study using fuzzy based classifiers. Geocarto International, 29(2), pp.211-225.

Tso, B., and Mather, P.M., (Second ed.) 2009. Classification Methods for Remotely Sensed Data, CRC Press, Boca Raton, pp.56-69.

Tucker, C.J., 1979. Red and photographic infrared linear combinations for monitoring vegetation. Remote Sensing of the Environment, 8(2), pp.127-150.
United States Geographical Survey (USGS), 2005. Earthquake Hazards Program, Magnitude 7.6-Pakistan 2005 October 8 03:50:40 (UTC), available online at: http://earthquake.usgs.gov/eqinthenews/2005/usdyae/ (accessed on 25 September 2017) 